\title{
Rancang Bangun Sistem Jaringan Menggunakan Linux Sabily pada Laboraturium Akademi Ilmu Komputer (AIKOM) Ternate
}

\author{
Sitna Hajar Hadad \\ Program Studi Teknik Komputer \\ Akademi Ilmu Komputer Ternate \\ sitnahajar@gmail.com
}

\begin{abstract}
Abstrak
Tujuan Penelitian ini adalah Untuk merancang dan mengimplementasikan jaringan protokol IPv4 pada Kampus Aikom Ternate, Penelitian ini dilakukan pada Laboraturium Akademi Ilmu Komputer (AIKOM) Ternate. Teknik Pengumpulan data melaui Pustaka, Penilitian Lapangan, observasi dan interview, Metode Perancangan dan implementasi Jaringan menggunakan protokol IPv4 dengan system operasi Linux Sabily. Jaringan tersebut dibuat dengan menggunakan router yang terkoneksi IPv4 ke internet, Pengujian menggunakan Sistem Operasi Linux Sabily, data yang diuji secara realtime mengenai suhu, kecepatan transfer data dan ketersediaan sumber daya. dengan adanya Rancang Bangun Sistem Jaringan Menggunakan Linux Sabily diharapkan dapat mempermudah penyampaian materi, informasi dan proses belajar mengajar antar komputer di laboratorium Akademi Ilmu Komputer (AIKOM) Ternate
\end{abstract}

\section{Kata kunci: Rancang, Sistem jaringan, Linux Sabily}

\begin{abstract}
The purpose of this research is to design and implementation network protocol IPv4 on the campus on Akademi Ilmu Komputer (Aikom) Ternate, This research was conducted at the Laboraturium Akademi Ilmu Komputer (Aikom) Ternate. The technique of data collection through the library, Penilitian, Field observation and interview, Network design and implementation method uses the IPv4 protocol with Sabily Linux operating system, The network created by using IPv4 router connected to the internet, Testing using the operating system Linux, Sabily tested in realtime data about temperature, the speed of data transfer and availability of resources, with the network system is expected to facilitate the delivery of content, teaching and learning processes and information between computers in the lab on Akademi Ilmu Komputer (Aikom) Ternate
\end{abstract}

Keywords: Design, Network System, Linux Sabily

\section{PENDAHULUAN}

Pemanfaatan jaringan komputer semakin menyebar luas di dunia teknologi informasi, dimana hampir semua sudah dikendalikan dengan sistem komputerisasi. Tuntutan akan pengembangan dan penerapan Teknologi Informasi (TI) dari waktu ke waktu semakin pesat. Seiring dengan perkembangan yang digunakan peralatan - peralatan canggih dalam rangka untuk meningkatkan kinerja kerja, maka semua komponen masyarakat harus mampu menyesuaikan diri dengan kondisi jaman. Apalagi ada tuntutan yang sangat mendesat baik dari pemerinta maupun masyarakat pada umumnya agar setiap lembaga pemerintah maupun swasta mampu memberikan tenaga atau pelayan secara efesien. Fasilitas tersebut salah satunya adalah penerapan teknologi dibidang pelayanan seperti pemanfaatan jaringan Internet Protokol Versi Empat 
(IPv4) untuk memperpendek kendala akses antara komputer ke komputer.

Dengan menggunakan penerapan sistem jaringan Internet Protokol Versi Empat (IPv4) akan dapat membantu mencegah masalah yang sebelumnya dalam pengiriman dan lebih capat dan akurat, seiring terjadinya mesin formation antara pengirim informasi dan penerima informasi

Dari hasil pengamatan, proses pengiriman dan pengaksesan data pada Kampus Aikom Ternate, masih sederhana dengan menggunakan flashdisk sebagai alat alternatif untuk memindakan file atau data sehingga mempercepat cara pengiriman data. Oleh karena itu, untuk mengantisipasi permasalahan dari hasil pengamatan sebelumnya maka peneliti mencoba merancang sebuah sistem jaringan Internet Protokol Versi Empat (IPv4), sehingga dapat dimanfaatkan oleh pemakai dalam penyampaian materi, informasi dan proses belajar mengajar antar komputer di laboratorium Akademi Ilmu Komputer (AIKOM) Ternate

\section{Rumusan Masalah}

Bagaimana Merancang dan Mengimplementasi Sistem Jaringan menggunakan Protokol IPv4 dengan Sistem Operasi Linux Sabily agar mempermudah Dosen dalam penyampaian materi, informasi dan proses belajar mengajar antar komputer

\section{Tujuan Penelitian}

Tujuan Penelitian ini adalah: Untuk merancang dan mengimplementasikan jaringan protokol IPv4 pada Kampus Aikom Ternate dan Mempermudah Dosen dalam proses belajar mengajar

\section{Manfaat Penelitian}

Manfaat dalam penelitian ini adalah: Menerapkan sistem jaringan dengan menggunakan Protokol IPv4 dengan Sistem Operasi Linux Sabily dan dapat meningkatkan kinerja dosen dalam belajar mengajar dan mempermudah untuk mengontrol sistem jaringan.

\section{Tinjauan Pustaka}

Indra Riyana Rahadjeng dan Ritapuspitasari, pada penelitian yang berjudul Analisis Jaringan Area Network (LAN) Pada PT.Mustika Ratu Tbk Jakarta Timur mengatakan PT Mustika Ratu Tbk merupakan perusahaan yang bergerak di bidang perindustrian jamu dan kosmetik tradisional Indonesia, dan memiliki banyak cabang di berbagai negara, memanfaatkan jaringan LAN untuk menghubungkan komputer satu dengan komputer lainnya. Pada jam-jam tertentu banyak client yang menggunakan jaringan secara bersamaan sehingga koneksi menjadi lambat. Terdapat client yang tidak mendapat IP, diakibatkan terserang oleh virus. Untuk itulah penulis melakukan penelitian pada jaringan LAN PT Mustika Ratu Tbk agar dapat membantu menangani permasalahan yang terjadi. LAN tergolong jaringan komunikasi kecepatan tinggi dan sifatnya dipengaruhi oleh media transmisi bersama dengan topologi dan protokol yang digunakan. Topologi yang digunakan dalam jaringan yang terbentuk di PT Mustika Ratu adalah topologi bintang atau star, dan Jaringan Local Area Network (LAN) yang ada pada PT. Mustika Ratu Tbk Jakarta-Timur (Ciracas) menggunakan jaringan VPN IP tunnel by mikrotik

Stefen Wongkar, Alicia Sinsuw, Xaverius Najoan, dalam Judul Analisa Implementasi Jaringan Internet Dengan Menggabungkan Jaringan LAN Dan WLAN Di Desa Kawangkoan Bawah 
Wilayah Amurang II, menguraikan bahwa Internet, merupakan jaringan global yang mendunia. Data, Informasi, bahkan Privasi telah menjadi bagian yang tak terpisahkan dalam internet. Mengakses internet, hampir sama halnya dengan menjelajah informasi dunia. Di jaman sekarang ini, internet bukan lagi merupakan kebutuhan tambahan malainkan menjadi kebutuhan pokok bagi para pengusaha, pelajar, dan berbagai pihak. Dan permasalahan tersebut di temukan di Desa Kawangkoan Bawah Wilayah Amurang II. Penelitian ini menggunakan Metode Pengumpulan data yang melingkupi Studi Pustaka, Observasi/Studi Lapangan, dan Wawancara langsung serta Metode Pengembangan Sistem Menggunakan NDLC yang telah di terapkan kepada masyarakat setempat maka telah di bangun sebuah jaringan internet dengan menggabungkan jaringan LAN (Local Area Network) dan WLAN (Wireless Local Area Network) yang cukup memadai.

SMK Negeri 1 Pulau Makian merupakan salah satu Sekolah Menengah Kejuruan yang terdapat pada pulau Makian Provinsi Maluku Utara, yang dalam mengelola dan bertukar datanya antar komputer satu dengan komputer yang lain masih bersifat manual dan sederhana yaitu dengan menggunakan flashdisk sebagai alat alternatif untuk memindahkan file, dikarenakan waktu yang dibutuhkan dalam memindahkan file dari komputer yang satu dengan yang lain sangat lama sehingga dianggap kurang efisien. Penilitian ini bertujuan merancang Wireless Fidelity (Wi-Fi) berbasis Windows Server 2008 Enterprise pada SMK Negeri 1 Pulau Makian, Metode pengumpulan data menggunakan Studi literatur mengenai teori-teori atau konsep mengenai Wireless
Fidelity (Wi-Fi) dan Studi Lapangan, melihat secara langsung data sistem yang berjalan yang ada pada SMK Negeri 1 Pulau Makian, dengan dibangunnya jaringan Wifi Menggunakan Sistem Operasi Windows Server 2008 pada SMK Negeri 1 Pulau Makian diharapkan dapat mempermudah proses pengiriman data secara cepat dan efisien

\section{LANDASAN TEORI}

\section{Pengertian Sistem jaringan}

Menurut sofana (2013:3) “jaringan komputer adalah suatu himpunan interkoneksi sejumlah komputer, dalam bahasa populer dapat di jelaskan bahwa jaringan komputer adalah kumpulan beberapa komputer, dan perangkat lain seperti router, switch dan sebagainya". Alat yang bisa terhubung dengan satu lainya Untuk memudahkan memahami jaringan computer para ahli sudah membagi beberapa klasifikasi, di antaranya:

1. Berdasarkan area atau skala.

2. Berdasrkan media penghantar.

3. Berdasarkan fungsi.

\section{Local Area Network (LAN)}

Local Area Network (LAN) merupakan jaringan komputer terkecil untukpemakaian pribadi. Local Area Network (LAN) memiliki skala jangkauan mencakup $1 \mathrm{KM}$ hingga $10 \mathrm{KM}$, dalam bentuk koneksi wired (kabel), wireless (nirkabel), maupun kombinasi keduanya.(Putu Agus, 2014 : p 32)

\section{Metropolitan Area Netwok (MAN)}

MAN pada dasarnya merupakan versi yang lebih besar dari LAN. MAN bisa berupa gabungan dari LAN - LAN yang terpisah yang dihubungkan dengan jalur transmisi yang dinamakan backbone. Biasanya merupakan jaringan komputer 
yang menghubungkan antar perusahaan dalam satu wilayah kota.(Todd Lammle, 2008)

\section{Wide Area Network (WAN)}

WAN (Wide Area Network) adalah sebuah pengaturan yang digunakan untuk menghubungkan LAN-LAN bersama melalui sebuah network DCE (Data Comunication Equipment), biasanya, sebuah WAN adalah sebuah koneksi leasedline atau dialup yang melalui sebuah network PSTN. Contoh-contoh protokol WAN termasuk, framerelay, PPP, ISDN, HDLC (Todd Lammle, CCNA Study Guide hal 709).

\section{Topologi}

Topologi jaringan merupakan gambaran pola hubungan antara komponenkomponen jaringan, yang meliputi komputer server, komputer client atau workstation, hub atau switch, pengkabelan dan komponen jaringan yang lain Madcoms (2015:6).

Pada jaringan komputer, dikenal setidaknya enam buah topologi pada jaringan komputer. Keenam jenis topologi pada jaringan komputer tersebut memiliki karakteristik, kelebihan, dan kekurangan masing-masing. Keenam topologi pada jaringan komputer ini meliputi Topologi Bus, Topologi Star, Topologi peer to peer (P2P), Topologi Ring, Topologi Tree, dan Topologi Mesh. (Putu Agus, 2014 : p 18)

\section{TCP/IP}

Menurut Sugeng ( 2014:63 ) "pada prinsip dasarnya, suatu komunikasi data merupakan proses pengiriman data dari satu komputer ke komputer yang lain, untuk terselenggaranya proses pengiriman paket data tersebut", terdapat beberapa permasalahan yang sangat rumit diantaranya adalah harus adanya kesamaan bahasa antara satu komputer dengan komputer yang lain agar dapat berkomunikasi, selain itu adalah bagaimana paket data tersebut dapat dikirim ke komputer yang lain sesuai tujuanya, terlebih lagi bila hubungan komputer tersebut tidak berada pada lokasi jaringan yang sama. Untuk kebutuhan ini komputer harus ditambahkan alat khusus yang dikenal selanjutnya sebagai NIC (Network Interface Card), Jenisnya bermacam macam tergantung media fisik yang digunakan untuk mentransfer data.

\section{Sistem Operasi Linux Sabily}

Sistem operasi Linux Sabily yang sebelumnya dikenal dengan Ubuntu Muslim Edition merupakan sistem operasi berbasis open source distribusi Linux turunan Ubuntu yang diperuntukkan bagi ummat muslim. Sabily tersedia dari paket ubuntu yang dikostumisasi sehingga di dalamnya tersedia berbagai paket - paket aplikasi Islam, Sabily sangat cocok digunakan bagi pengguna Ubuntu yang beragama Islam. Ubuntu sangat mudah digunakan bagi pemula, di dalamnya terdapat aplikasi perkantoran, grafis, video dsb. sehingga dengan Sabily pun diharapkan mudah digunakan. Dengan Sabily kita akan mendapatkan berbagai aplikasi Islam seperti (aplikasi pengingat salat, aplikasi belajar Al-Qur'an, Kalender Hijriyah, cursor mouse yang selalu berdzikir dsb.) dan tentu dengan desain/tema yang bernuansa Islam.

\section{METODE PENELITIAN}

\section{Tempat Penilitian}

Penelitian ini dilakukan pada Laboraturium Akademi Ilmu Komputer (AIKOM) Ternate 


\section{Teknik Pengumpulan Data}

a. Penilitian Pustaka (Libarary Research), Kajian pustaka merupakan data utama dalam menyusun penelitian ini, dengan cara mengumpulkan data berbagai referensi yang berkaitan dengan bidang ilmu yang di teliti.

b. Penilitian Lapangan (field research) Penilitian Lapangan adalah jenis pengumpulan data dengan melakukan pengamatan lansung dilapangan. Dengan menggunakan teknik sebagai berikut:

c. Teknik observasi adalah teknik yang dilakukan dengan cara mengadakan pengamatan secara lansung mengenai sistem yang berjalan.

d. Teknik interview (wawancara) adalah untuk menggunakan data yang relevan dengan variable yaitu mendengarkan wawancara terhadap pihak-pihak yang berwewenang berhubungan dengan penilitian.

Metode perancangan dan implementasi jaringan menggunakan protokol IPv4 dengan system operasi Linux Sabily. Jaringan tersebut dapat dibuat dengan menggunakan Sistem sebagai router yang terkoneksi IPv4 ke internet, proses monitoring jaringan komputer dapat dilakukan tanpa harus berada dalam lingkup jaringan atau dengan kata lain, bisa dimonitor jarak jauh dimanapun dan kapanpun selama terhubung jaringan Internet. Pengujian menggunakan Sistem Operasi Linux Sabily, data yang diuji secara realtime mengenai suhu, kecepatan transfer data dan ketersediaan sumber daya.

\section{Kerangka Berpikir}

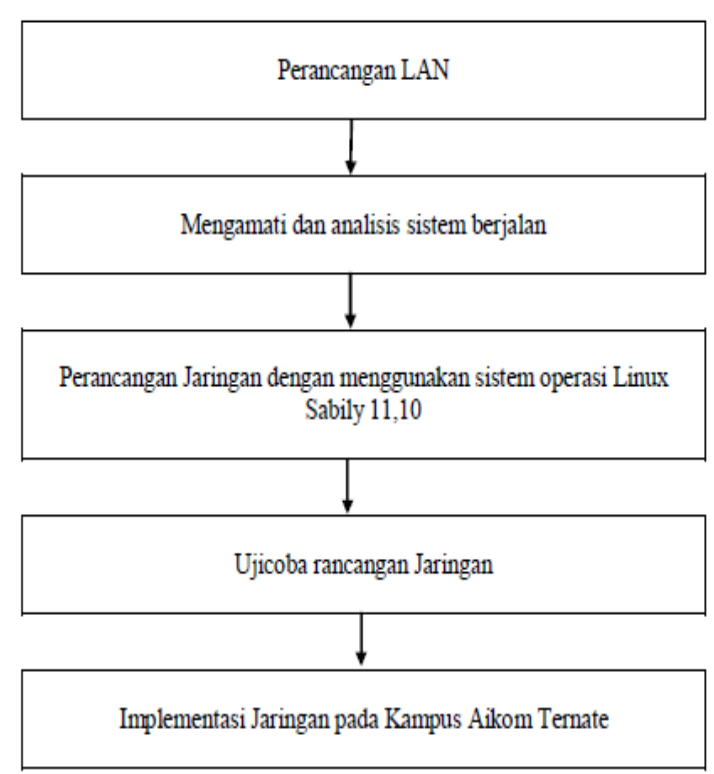

Gambar 1. Kerangka Berpikir

\section{ANALISIS DAN PERANCANGAN}

Dari hasil penilitian yang peniliti lakukan pada Kampus Aikom Ternate di Ruang Lab Sistem yang digunakan adalah sistem tanpa menggunakan jaringan LAN. Oleh karena itu, pentingnya jaringan LAN di dalan Lab untuk mempermudah dosen dalam proses belajar mengajar khususnya mata kulia praktikum. Maka dari itu, penulis mengusulkan sistem baru agar mempermudah dosen untuk sharing data dalam proses belajar mengajar yang sedang berlangsung.

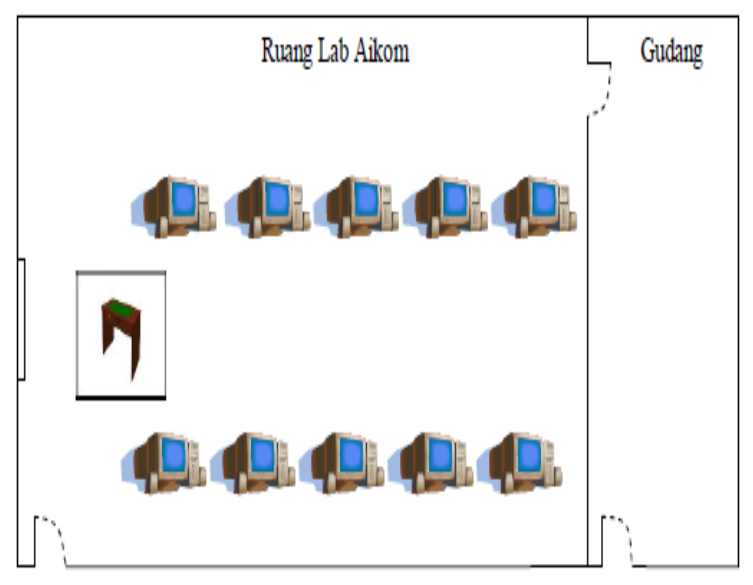

Gambar 2. Sistem berjalan

Dilihat dari sistem yang berjalan di atas maka peneliti mengusulkan sistem yang 
baru yaitu perancangan jaringan IPv4 menggunakan sistem operasi linux sabily.

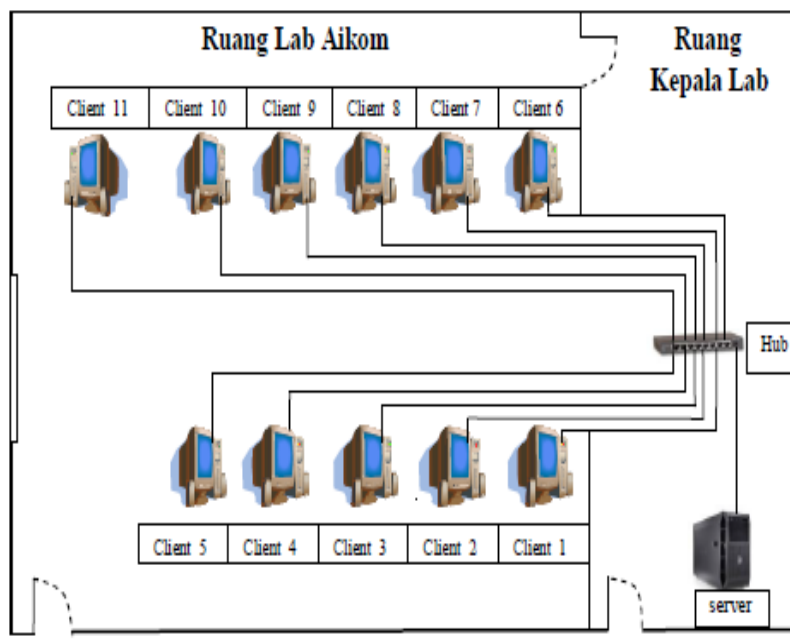

Gambar 3. Analisis Sistem yang diusulkan

\section{IMPLEMENTASI DAN PEMBAHASAN} Perangkat yang dibutuhkan

a. Linux Sabily 11.10 (server).

b. Windows 7 (client).

c. Driver-driver.

d. Laptop : Asus 14 Inc

e. Processor : Intel Atom CPU N2800 1,86GHz

f. Memory (Ram) : $2 \mathrm{~Gb}$.

g. Hardisk : $320 \mathrm{~Gb}$.

h. Server

i. Client / Workstation

j. Access Point.

\section{Proses Instalasi Jaringan}

a. Langkah awal yang di lakukan yaitu buka web browser anda lalu pada addres bar ketikkan http://192.168.0.1 kemudian tekan enter

b. Maka akan muncul jendela user name dan password, pada user name ketik "admin" kemudian pada bagian password ketik juga "admin" kemudian klik OK.

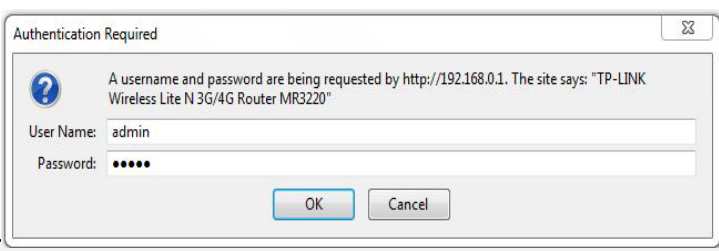

Gambar 4. Tampilan user name dan password untuk masuk ke panel

c. Setelah anda mengklik OK tadi, maka akan tampil jendela konfigurasi Access Linksys. Klik tab Wireless, di jendela inilah anda akan memasukan nama jaringan wireless yang akan anda gunakan, atau yang sering disebut dengan SSID (Service set indentifier).

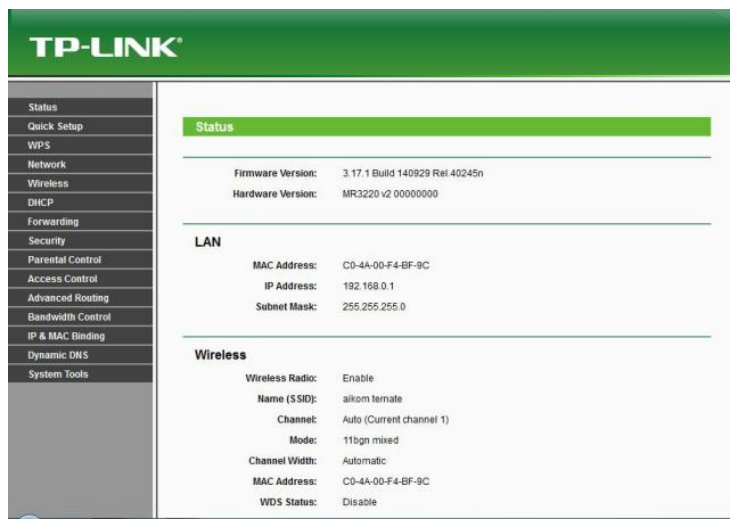

Gambar 5. Tampilan awal Menu konfigurasi

d. Selanjutnya masuk di wireless setting, SSID TP-LINK di rubah menjadi AIKOM TERNATE

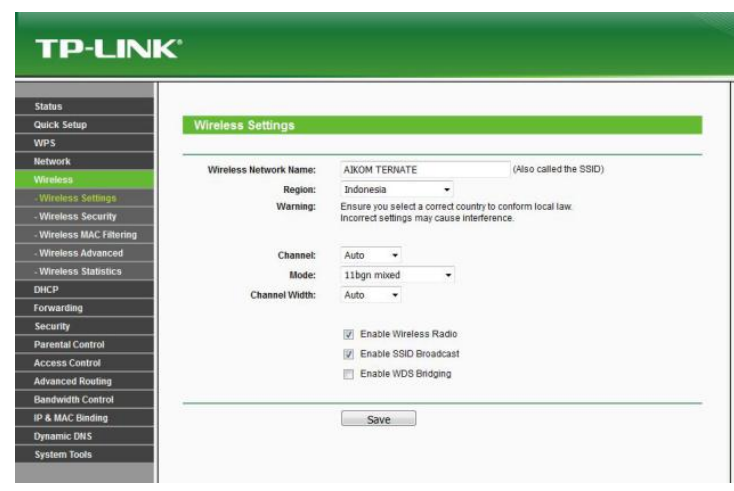

Gambar 6. Tampilan menu setting SSID

e. Masuk "DHCP Setting" untuk mengatur IP star anddress dan end anddress, lalu pilih enable untuk setting secara otomatis. 


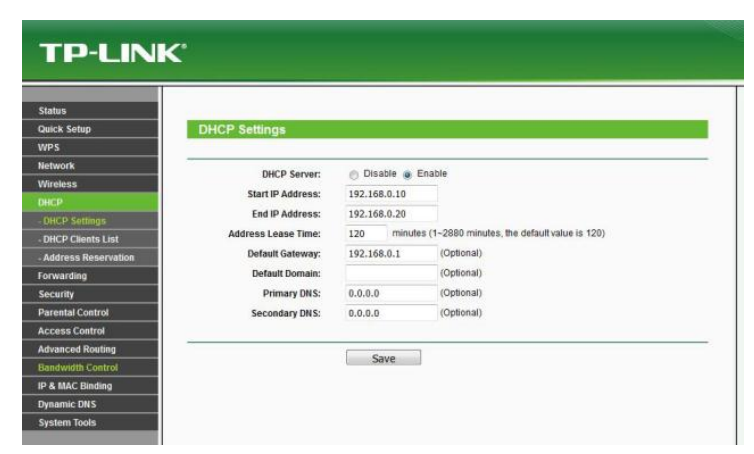

Gambar 7. Tampilan Menu $D H C P$

f. Selanjutnya pilih Reboot untuk melakukan restart otomatis

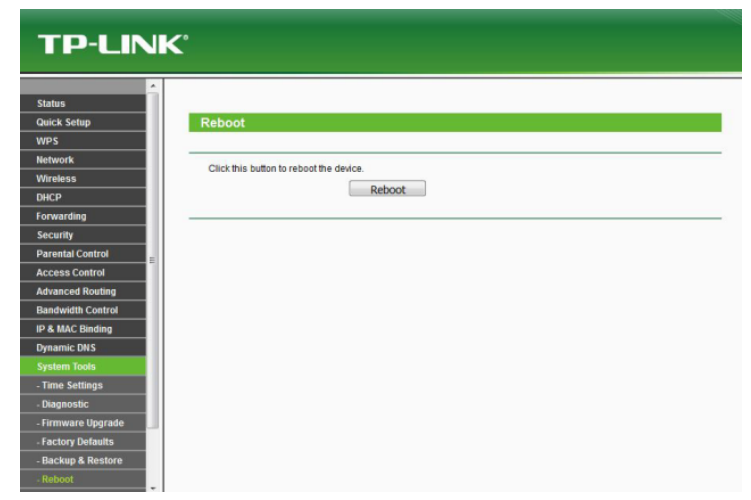

Gambar 8. Tampilan Menu reboot sistem

g. Double klick pada icon wireless connection, akan muncul dialog seperti pada gambar di bawah untuk mengetahui koneksi yang telah diatur.

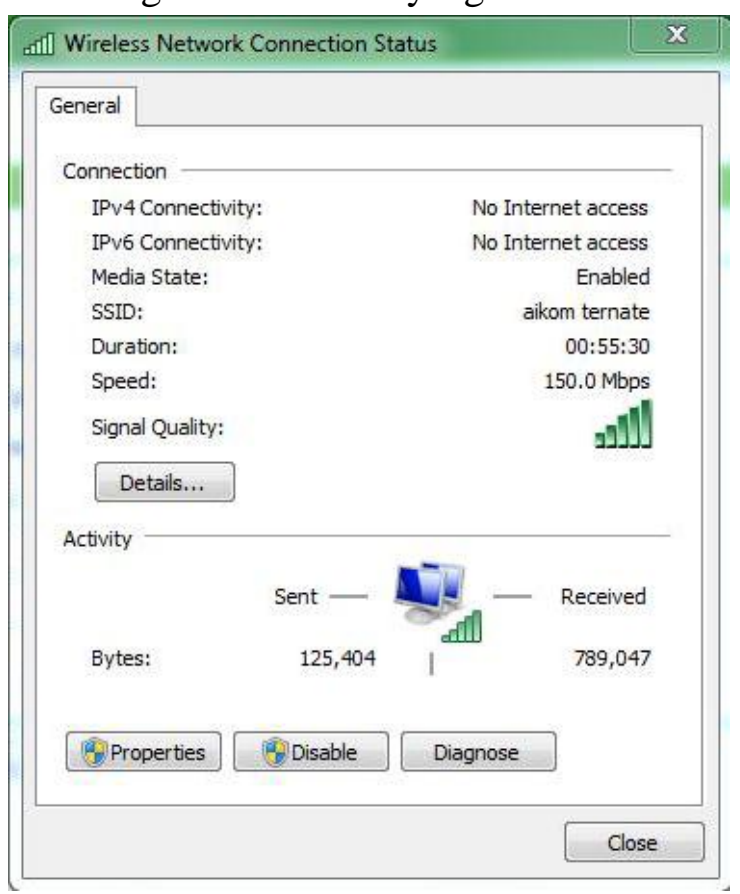

Gambar 9. Tampilan setting koneksi

\section{Pembahasan Hasil Instalasi}

Dari hasil instalasi pada penelitian yang telah dilakukan pada Kampus Aikom Ternate dapat ditulis bahwa jaringan WLAN merupakan teknologi yang bertujuan untuk menggantikan jaringan kabel yang menghubung kanterminal komputer dengan jaringan, dengan begitu komputer dapat dipindahkan dengan bebas dan tepat dapat berkomunikasi dalam jaringan dengan kecepatan transmisi oleh IEEE dengan kode 802.11 yang bertujuan untuk menyamakan semua teknologi nirkabel yang digunakan dibidang komputer dan untuk menjamin interoperabilitas antar semua produkproduk yang menggunakan standar ini, standar ini menggunakan gelombang 2.4 $\mathrm{GHz}$ untuk mentransmisikan data, standar ini juga masih berdasarkan pada model $I S O$, hanya berada pada layer data Link dan phisikalnya.

\section{KESIMPULAN}

Setelah dilakukan pembahasan dan uraian-uraian pada bab-bab sebelumnya, maka dapat ditarik beberapa kesimpulan yaitu Tujuan melakukan pertukaran data/informasi secara otomatis dengan menggunakan LAN dengan Linux Sabily sebagai sistem operasi pada komputer server. sehingga dapat mempermudah dalam proses pertukaran data/informasi.

\section{Saran}

Untuk menyempurnakan penelitian ini maka perlu disarankan untuk pengembangan berikut Agar dapat memperhatikan keamanan sistem jaringan terutama saat melakukan pertukaran data/informasi 


\section{DAFTAR PUSTAKA}

Ayeix 2009," Kelebihan dan Kekurangan Linux “

Sofana Iwan (2013). "CISCO CCNA \& Jaringan Komputer, (Edisi Revisi)." Bandung: Informatika

Winarno Sugeng, Membahas konsep dan Teknik Implementasi TCP/IP dalam jaringan komputer. Bandung: Modula, 2015.

Pratama, I Putu Agus Eka, (2014), Handbook Jaringan Komputer, Teori dan Praktik Berbasiskan Open Source, Informatika : Bandung.

Lammle, Todd. CCNA Certified Network Associate Study Guide : Exam 640 801 6th Edition

Indra Riyana Rahadjeng, Ritapuspitasari, Analisis Jaringan Area Network (LAN) PAda PT.Mustika Ratu Tbk Jakarta Timur, Jurnal PROSISKO Vol. 5 No. 1 Maret 2018, e-ISSN: 2597-9922, p-ISSN: 2406-7733

Madcoms, 2016. Manajemen sistem jaringan computer dengan Mikrotik RouterOS. Yogyakarta: Andi Offset

Stefen Wongkar, Alicia Sinsuw, Xaverius Najoan, Analisa Implementasi Jaringan Internet Dengan Menggabungkan Jaringan LAN Dan WLAN Di Desa Kawangkoan Bawah Wilayah Amurang II, E-journal Teknik Elektro dan Komputer vol. 4 no.6 (2015), ISSN 2301-8402.

Wikipedia bahasa Indonesia, ensiklopedia bebas, Sabily (sistem operasi), https://id.wikipedia.org/wiki/Sabily_( sistem_operasi).

Hasrin Kasim, Sandi Kamarullah, Membangun Jaringan Wifi Menggunakan Sistem Operasi Windows Server 2008 pada SMK Negeri 1 Pulau Makian, Jurnal Ilmiah ILKOMINFO - Ilmu Komputer \& Informatika Vol 1, No 1 (2018), eISSN : 2621-4970, pISSN : 26214962 